\title{
Airway remodelling assessed by sputum and high-resolution computed tomography in asthma and COPD
}

\author{
A.M. Vignola*, F. Paganin\#, L. Capieu\#, N. Scichilone*, M. Belliaף, L. Maakel", V. Bellia*, P. Godard", \\ J. Bousquet ${ }^{\#}$, P. Chanez
}

Airway remodelling assessed by sputum and high-resolution computed tomography in asthma and COPD. A.M. Vignola, F. Paganin, L. Capieu, N. Scichilone, M. Bellia, L. Maakel, V. Bellia, P. Godard, J. Bousquet, P. Chanez. C ERS Journals Ltd 2004. ABSTRACT: It is not known whether sputum elastase, metalloproteinase (MMP)-9 and tissue-inhibitor metalloproteinase (TIMP)-1 are related to structural changes of the airways, as assessed by high-resolution computed tomography (HRCT) scan.

The relationships between these markers and the magnitude of structural changes of the airways in asthma and chronic obstructive pulmonary disease (COPD) were assessed. Induced sputum and HRCT scan were performed in 30 asthmatics (14 mild and 16 severe) and in 12 patients with COPD.

A greater extent of HRCT scan abnormalities was found in COPD than in severe and mild asthmatics. HRCT scan abnormalities correlated with the degree of airway obstruction in COPD and in severe asthma. HRCT scan abnormalities also correlated with the levels of sputum elastase both in COPD and in severe asthma. HRCT scan abnormalities were associated with sputum MMP-9/TIMP-1 ratio in mild asthma, severe asthma and COPD.

In conclusion, this study demonstrates that sputum elastase and the metalloproteinase-9/tissue-inhibitor metalloproteinase-1 ratio are associated with the magnitude of high-resolution computed tomography scan abnormalities of the airways in asthma and chronic obstructive pulmonary disease, and suggests that the levels of these markers reflect the extent of structural changes of the airways.

Eur Respir J 2004; 24: 910-917.
Institutes of *Respiratory Diseases and Radiology, University of Palermo, Palermo, Italy. \#Dept of Respiratory Diseases and INSERM unit 454, CHU Montpellier, Montpellier, France.

Correspondence: A.M. Vignola

Istituto di Medicina Generale e Pneumologia

Cattedra di Malattie Respiratorie

Università di Palermo

Via Trabucco 180

90146 Palermo

Italy

Fax: 390916882165

E-mail: vignola.am@iol.it

Keywords: Airway remodelling asthma

chronic obstructive pulmonary disease high-resolution computed tomography sputum

Received: March 222003

Accepted after revision: August 22004
Asthma and chronic obstructive pulmonary disease (COPD) share a condition of chronic inflammation of the airways, which is followed, to various extents and with different features, by a healing process that may lead to airway remodelling. Although the mechanisms of remodelling appear to be heterogeneous, an abnormal extracellular matrix (ECM) degradation and deposition may play an important role in the development of structural alterations of the airways, contributing to airway stiffness and to irreversible airflow obstruction [1]. Such remodelling within the airway wall is to be attributed mainly to qualitative and quantitative changes of ECM proteins, resulting from an imbalance between proteases and their inhibitors.

Inflammation in asthma and COPD is associated with increased production of active elastase, which can promote fibroblast migration through the ECM, as well as the degradation of elastic fibres [2, 3]. ECM homeostasis is also influenced by the balance between metalloproteinases (MMP) and their specific tissue-inhibitor metalloproteinases (TIMP), in such a way that increases of TIMP over MMP (or vice versa) can either lead to collagen deposition or degradation [4, 5]. In asthma and COPD, several studies have shown that there is an increase of TIMP-1 over MMP-9 levels both in bronchoalveolar lavage and sputum, which may be responsible for a trend towards collagen deposition in the airway

For editorial comments see page 893. wall, and for the development of an exaggerated airway narrowing [4, 6-10]. This evidence has led to the hypothesis that, in asthma and COPD, the imbalance between elastase over anti-elastase, and between MMP-9 over TIMP-1, may contribute to structural changes of the airways and to a functional impairment; although attractive, this hypothesis has never been tested, mainly due to the difficulties in studying airway remodelling in a noninvasive fashion.

However, with the advances in the field of lung imaging, our ability to noninvasively quantify structural changes of the airways has been significantly improved both in asthma and COPD [11-15], making it possible to establish a close relationship between structural and functional abnormalities. Indeed, in asthma, the use of high-resolution computed tomography (HRCT) has allowed the demonstration of several airway wall abnormalities, whose extent significantly correlated with the clinical severity of the disease $[12,13,16]$, the impairment of lung function and the magnitude of bronchial hyperresponsiveness $[11,17]$, three parameters that are likely to be due to airway remodelling.

In order to assess, in an integrated manner, biochemical, structural and functional parameters in the same group of asthmatic and COPD subjects, this study was undertaken to test the hypothesis that, in asthmatic and COPD patients, the increased levels of active elastase, MMP-9 and TIMP-1 may account for HRCT scan abnormalities and functional changes that characterise these diseases. 


\section{Materials and methods}

\section{Subjects}

A total of 30 asthmatic subjects were selected according to the criteria of the American Thoracic Society [18]. Asthma severity was assessed according to Global Initiative for Asthma (GINA) criteria [19]. None of the subjects participating in the study was a current smoker. Subjects who had an upper or lower respiratory tract infection during the month preceding the test, or who experienced a severe exacerbation of asthma resulting in hospitalisation, were excluded from the study. For the purpose of the study, subjects were divided into two groups. The first group consisted of 14 corticosteroidnaïve subjects (eight males, 29-69 yrs) with mild persistent asthma, who attended the current authors' outpatient clinic (Dept of Respiratory Diseases, CHU Montpellier, Montpellier, France) for the first time. This group was defined as mild asthmatics. The second group consisted of 16 severe asthmatic patients (nine males, 26-66 yrs), selected as previously described [20]. They had persistent asthma that required a q.d. dose of inhaled corticosteroid $(2,000 \mu \mathrm{g}$ fluticasone propionate) or oral prednisone, long-acting $\beta_{2}-$ agonists $\left(100 \mu \mathrm{g}\right.$ salmeterol) and short-acting $\beta_{2}$-agonists as required. These patients were all considered as corticosteroid dependent since, in the past $2 \mathrm{yrs}$, the attempt to wean them from the systemic treatment had always failed (follow-up at $\leqslant 3 \mathrm{yrs}$ ). They were studied whilst in stable clinical conditions, according to the asthma-control questionnaire [21].

In total, 12 COPD patients (11 males, 48-77 yrs) took part in the study. COPD was defined as a disorder characterised by abnormal expiratory flow test [22] and, although no definitive cut-off limit was available at the time of the study, only patients with forced expiratory volume in one second (FEV1) capacities of $<70 \%$ of the predicted values were studied. The Global Initiative for Chronic Obstructive Lung Disease (GOLD) criteria were not applied since they were not available when the study was carried out. COPD patients with a history of perennial allergic rhinitis and/or a positive diagnosis of immediate-type hypersensitivity [23], wheezing, an improvement of FEV1 capacity of $>12 \%$ from baseline or an absolute value of $200 \mathrm{~mL}$ following inhalation of $200 \mu \mathrm{g}$ of salbutamol were excluded. Smoking habit was carefully checked, and a minimum of 20 pack-yrs smoked was required for inclusion in the chronic bronchitis group. None of them had any upper or lower respiratory tract infection during the month preceding the test, and none of them was permitted to smoke the day of study. They were in a stable condition, their lung function being their best ever measured in the current authors' clinic. All investigations were performed on the same day. The study was performed after informed consent was obtained from the participants, and approval of the ethics committee of the hospital was obtained.

\section{Pulmonary function testing}

Pulmonary function test was performed using a Pneumoscreen (E. Jaeger Laboratories, Würzburg, Germany), and normal values were analysed according to KNUDSON et al. [24]. Carbon monoxide diffusing capacity of the lung ( $D \mathrm{~L}, \mathrm{CO})$ was measured using the single breath technique. Quality control and procedures of lung function testing were performed according to the European Respiratory Society guidelines $[25,26]$. Predicted normal values were determined using the equations of the European Community for Steel and Coal for all resting pulmonary function parameters $[25,26]$.

\section{Chest computed tomography scan}

Computed tomography (CT) scans of the chest were performed with a spiral CT scanner (LightSpeed 16; GE Healthcare, Paris, France) in high-resolution mode according to the method of MAYO et al. [27], as previously used by the current authors [12]. Briefly, only a conventional HRCT scan during full inspiration was performed [28]. CT scans of the chest were performed using the following parameters: $125 \mathrm{kV}$, $310 \mathrm{mAs}$, matrix size of $512 \times 512$, and a slice thickness of $1-1.25 \mathrm{~mm}$. A window level of -600 Hounsfield units (HU) was chosen, with a width of 1,600 HU, as generally recommended for the analysis of the bronchi and lung parenchyma [27, 29]. Several HRCT scan abnormalities were taken into account, as follows: 1) bronchial abnormalities (bronchiectasis) $[30,31]$ and thickness of peripheral bronchi [32];2) emphysema (centrolobular and bullous) [33]; and 3) peripheral linear hyperdensities [34]. Due to the difficulty of staging or prioritising the impact of radiographical abnormalities (bronchiectasis, emphysema and others) on the clinical outcomes of the disease $[35,36]$, each of the above permanent HRCT scan abnormalities was considered as contributing equally to the remodelling process $[12,37]$. Thus, a total score of HRCT scan abnormalities was calculated simply by summation, as previously published [37].

CT measurements were obtained in a blind fashion by two observers (L. Capieu and F. Paganin). The measurements were performed once and interobserver reproducibility was $\operatorname{good}(\kappa=0.7)$.

\section{Sputum induction}

Induced sputum was carried out according to the method of PIN et al. [38]. Sputum samples were immediately treated with 10\% dithiotreitol (Sigma Chemical, St Louis, MO, USA) and centrifuged. The supernatants were immediately frozen for subsequent analysis. A cytocentrifugation (Shandon, Runcorn, UK) was done on the cell pellet, and cells were enumerated using Diff-Quick (Imeb Inc., Chicago, IL, USA).

Total elastase was measured in sputum samples by a homogeneous enzyme immunoassay specific for human polymorphonuclear elastase (IMAC-Elastase; Kit Merck, Darmstadt, Germany) using the package insert [39], as previously described [5]. Levels $>20 \mu \mathrm{g} \cdot \mathrm{L}^{-1}$ can be measured. The activity of active neutrophil elastase was determined according to the technique of FUJITA et al. [3], as previously described [5].

Determinations of the absolute value of MMP-9 and TIMP-1 in induced sputum were performed by ELISA (MMP9-BIOTRAK ELISA and TIMP1-BIOTRAK ELISA; Amersham International plc, Little Chalfont, UK), as previously described [5]. These assays measure the total amount of each respective protein (MMP-9 and TIMP-1), whether free or complexed to one another or to matrix. The limits of detection are $4-128 \mathrm{ng} \cdot \mathrm{mL}^{-1}$ for MMP-9 and $3.13-50 \mathrm{ng} \cdot \mathrm{mL}^{-1}$ for TIMP-1.

\section{Statistical analysis}

Results are given as medians (interquartile range). The nonparametric Kruskall-Wallis test was used to compare the outcomes of the study within the three groups. The MannWhitney U-test was used for pairwise comparisons between the study groups. To evaluate whether an association exists between the biological outcomes and structural alterations described with the HRCT scan, the nonparametric correlation 
analysis (Spearman rank test) was used. For multiple comparisons, Bonferroni's correction was applied. p-Values of $\leqslant 0.05$ were considered statistically significant.

\section{Results}

Demographic characteristics of the patients are reported in table 1. Patients with COPD were significantly older than both groups of asthmatics. Airflow obstruction was significantly greater in COPD and severe asthmatics than in mild asthmatics $(\mathrm{p}<0.001)$. As expected, $D \mathrm{~L}, \mathrm{CO}$ was significantly decreased in COPD when compared with mild $(\mathrm{p}<0.0003)$ and severe asthmatics $(\mathrm{p}<0.007)$. Arterial oxygen tension $\left(\mathrm{Pa}, \mathrm{O}_{2}\right)$ was significantly lower in COPD than in severe and mild asthma $(\mathrm{p}<0.016$ and $\mathrm{p}<0.001$, respectively) and in severe asthmatics by comparison with mild asthmatics $(\mathrm{p}<0.016)$.

\section{High-resolution computed tomography scan}

Eight out of 14 mild asthmatics showed HRCT scan abnormalities with a maximal score of 5 (fig. 1). Most of the abnormalities were related to the bronchial tree, and no emphysema of the lung was observed.

Three severe asthmatics had a normal HRCT scan. In the other patients, abnormalities were mainly related to bronchi, whereas emphysema was recorded in three subjects. The number of lesions was significantly higher than in milder asthmatics (mean score difference: $7 ; \mathrm{p}<0.003$ ).

All COPD patients had HRCT scan abnormalities that were mainly related to the parenchyma (emphysema), but bronchiectasis was also observed. The total number of lesions was significantly greater in COPD individuals as compared with mild (mean score difference: 19; $\mathrm{p}<0.0001$ ) and severe asthmatics (mean score difference: $12 ; \mathrm{p}<0.003$ ).

Interestingly, HRCT findings correlated with the degree of airway obstruction, as assessed by FEV1, in severe asthmatics ( $\rho=-0.78, p=0.003)$ and the COPD subjects $(\rho=-0.70, p=0.02)$, but not in the mild asthmatic group $(\rho=-0.03, p=0.92$; fig. 2$)$. Also, both in the COPD group and the severe asthmatic group, HRCT scan score significantly correlated with $D$ L,CO values $(\rho=-0.53, p=0.04$, and $\rho=-0.74, p=0.01$, respectively).

\section{Cellular content in induced sputum}

The cellular content is reported in table 2 . The percentage of macrophages was higher in mild asthmatics than in COPD or severe asthmatics $(\mathrm{p}<0.001$ and $\mathrm{p}<0.0004$, respectively). The percentage of neutrophils was greater in mild asthmatics than in severe asthmatics $(p<0.003)$. The percentage of eosinophils was increased in severe asthma by comparison with mild asthma $(p<0.009)$. There was no significant correlation between cell numbers or percentages and FEV1 levels or HRCT scan scores.

\section{Mediator levels in induced sputum}

Table 3 shows the mediator levels in induced sputum. The levels of total elastase were higher in COPD subjects than in severe $(\mathrm{p}<0.001)$ and mild $(\mathrm{p}<0.001)$ asthmatics. Sputum of COPD subjects was also characterised by higher levels of active elastase than those measured in the other two study groups $(\mathrm{p}=0.01$ and $\mathrm{p}=0.003$ for severe and mild asthmatics, respectively).

The levels of MMP-9 were not significantly different among the three groups. Conversely, TIMP-1 was increased in COPD and significantly higher than that of mild asthmatics $(\mathrm{p}<0.0007)$. MMP-9/TIMP-1 ratio was reduced in COPD as compared with severe and mild asthma, but the difference did not reach statistical significance.

Nonparametric correlations within each study group showed that active elastase levels were significantly associated with HRCT scan score in severe asthma and in COPD $(\rho=-0.9$, $\mathrm{p}<0.008$ and $\rho=-0.9, \mathrm{p}<0.005$, respectively; fig. 3 ), but not in the mild asthmatic group $(\rho=-0.3, p=0.19)$. In addition, in COPD and severe asthmatic subjects, the levels of active elastase were found to be inversely and significantly correlated with airway obstruction, as assessed by FEV1 values $(\rho=-0.6, p<0.03$ and $\rho=-0.7, p<0.003$, respectively). A significant correlation was also found between HRCT scan score and MMP-9/TIMP-1 ratio (mild asthma: $\rho=-0.8, p<0.003$; severe asthma: $\rho=-0.7, p<0.004$; COPD: $\rho=-0.6, p<0.04$ ), although this correlation seems to be affected by one single observation (fig. 4).

\section{Discussion}

The main result of this study is that a relationship exists between increased levels of active elastase and overproduction

Table 1.-Demographic characteristics of the patients

\begin{tabular}{|c|c|c|c|c|c|c|}
\hline & \multirow[t]{2}{*}{ MA } & \multirow[t]{2}{*}{ SA } & \multirow[t]{2}{*}{ COPD } & \multicolumn{3}{|c|}{ Statistical analysis } \\
\hline & & & & $\mathrm{MA} / \mathrm{SA}$ & MA/COPD & $\mathrm{SA} / \mathrm{COPD}$ \\
\hline Subjects $n$ & 14 & 16 & 12 & & & \\
\hline Females $\mathrm{n}$ & 6 & 7 & 1 & & & \\
\hline Age yrs & $52.5(45-58)$ & $53.5(35-65)$ & $71(56.5-72.5)$ & NS & $<0.01$ & $<0.01$ \\
\hline Smoking pack-yrs & 0 & 0 & $55(42.5-80)$ & & & \\
\hline FEV1 L & $3.08(2.16-3.52)$ & $1.44(1.30-2.04)$ & $1.41(1.16-1.52)$ & $<0.001$ & $<0.001$ & NS \\
\hline FEV1 $\%$ pred & $93(86-100)$ & $54.5(44.5-62)$ & $50.5(45-55)$ & $<0.001$ & $<0.001$ & NS \\
\hline $\mathrm{Pa}, \mathrm{O}_{2} \mathrm{mmHg}$ & $90.5(86-95)$ & $78.5(73.5-90.5)$ & $71.5(71-78.5)$ & $<0.016$ & $<0.001$ & $<0.016$ \\
\hline$D \mathrm{~L}, \mathrm{CO} \%$ pred & $103.5(86-118)$ & $94(79-100)$ & $61(52.5-73)$ & NS & $<0.0003$ & $<0.007$ \\
\hline CT scan score & $2(0-4)$ & $6.5(2.5-16)$ & $19(15-25.5)$ & $<0.01$ & $<0.001$ & $<0.01$ \\
\hline
\end{tabular}

Data are presented as median (interquartile range), unless otherwise stated. Statistical analysis was performed by the Mann-Whitney U-test and Bonferroni's correction. Data were considered statistically significant when $\mathrm{p}<0.016$. MA: mild asthma (untreated asthma); SA: severe asthma (corticosteroid-dependent asthma); COPD: chronic obstructive pulmonary disease; FEV1: forced expiratory volume in one second; $P$ a, $\mathrm{O}_{2}$ : arterial oxygen tension; $D \mathrm{~L}, \mathrm{CO}$ : carbon monoxide diffusing capacity of the lung; $\mathrm{CT}$ : computed tomography; $\mathrm{NS}$ : nonsignificant. $1 \mathrm{kPa}=0.133 \mathrm{mmHg}$. 


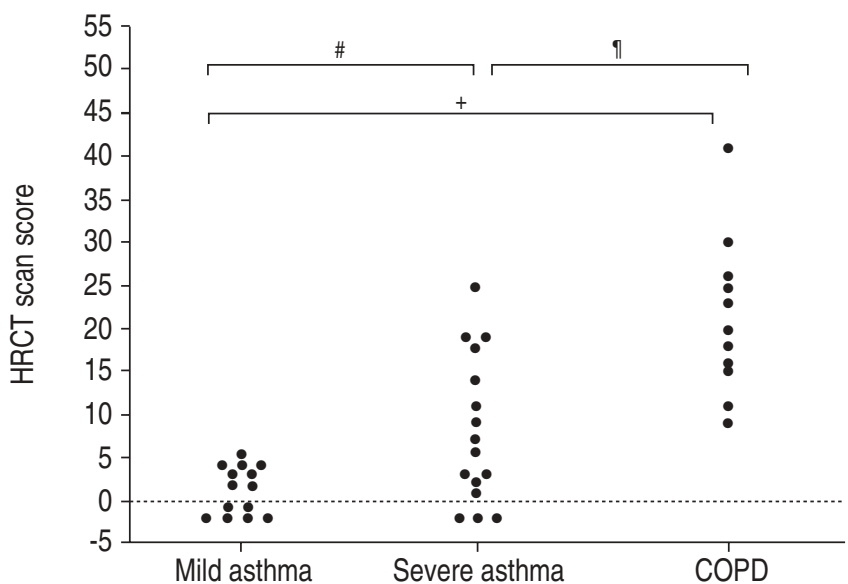

Fig. 1.-Quantification of high-resolution computed tomography (HRCT) scan score in mild asthma, severe asthma and chronic obstructive pulmonary disease (COPD). Statistical analysis was performed using the Mann-Whitney U-test. ${ }^{\#}: \mathrm{p}<0.03 ; ": \mathrm{p}<0.003$; $+\mathrm{p}<0.0001$.


Fig. 2. - Correlations between forced expiratory volume in one second (FEV 1 ) \% predicted and high-resolution computed tomography (HRCT) scan score in a) severe asthma and b) chronic obstructive pulmonary disease. Statistical analysis was performed using the Spearman rank test.

of TIMP-1 over MMP-9 with HRCT abnormalities in severe asthmatics and in COPD subjects. This observation further supports the concept that the levels of these biological markers of remodelling might reflect the extent of structural changes occurring within the airways. The present study also provides evidence in support of the usefulness of a HRCT scan technique to assess structural alterations of the airways.

HRCT scan has been proposed as an additional tool to assess pulmonary changes in long-standing diseases, such as asthma and COPD [40-42]. Moreover, by differentiating airway remodelling from parenchymal alterations, HRCT imaging could contribute towards distinguishing between asthma and COPD. Anatomical pulmonary changes, including bronchial wall thickening, emphysema, and bronchiectasis, have been demonstrated by HRCT scan in some studies [11-13, 37]. Therefore, this technique could provide relevant information in airway remodelling associated with a chronic inflammation of the airways. HRCT scan has been previously used to quantify abnormalities of the airways due to airway remodelling and it has been found that the HRCT scan score correlated with the severity of asthma and airflow obstruction $[12,43]$; conversely, conflicting results have been obtained on the relationship between HRCT-documented thickness of airway wall and hyperresponsiveness [17, 44], and, from these results, it can be derived that the issue of airway responsiveness is perhaps a more complex phenomenon than airway obstruction. The most plausible explanation for different results among studies may depend on the method that was employed to assess and quantify the structural alterations of the lung. In the current study, the HRCT outcome is represented by a final score that was obtained by counting the number of the observed lesions. Although a significant number of quantitative methods are now available, the current authors have arbitrarily chosen this method because it avoids the risk of underestimating the degree of pulmonary involvement. Indeed, this approach has the advantage of combining information from both airways and parenchyma. In a study performed in COPD subjects by NAKANO et al. [45], the evaluation of both airway wall thickness and the area of low attenuation of the lung (to assess the severity of emphysema) was shown to improve the estimation of pulmonary function abnormalities. The recent advantages in technology, with the use of new multi-slice CT scanners, together with the use of more objective and direct measurement of airway dimension and parenchymal abnormalities, such as the assessment of lung densities by density mask or histograms to evaluate the degree of emphysema, which are employed by all investigators, should increase the accuracy of the evaluation and minimise discrepancy between studies.

In the current study, it was demonstrated that HRCT scan abnormalities are more relevant in severe than mild asthma, suggesting that severe asthma is characterised by a greater extent of structural abnormalities of the airway wall. In addition, in severe asthmatics, it was shown that most of the HRCT scan abnormalities are due to bronchial alterations, which may play a role in the development of a severe expiratory flow limitation. Bronchial abnormalities were also detected by the CT scan in the COPD group. The observation of bronchiectasis in COPD patients is not controversial. Associations between emphysema and bronchiectasis are frequent and related to processes of traction and cicatrisation, reflecting a process of peri-bronchial fibrosis [46] and abnormal synthesis and degradation of ECM proteins, such as collagen and elastin. In the context of COPD, the current authors were also able to assess the parenchymal involvement, mostly emphysema. This is of great importance from a functional standpoint, in that it may account for the significant correlation between the HRCT scan alterations and the degree of impairment in DL,CO. Taken together, quantitative assessment of airway wall dimensions and parenchymal alterations with HRCT could provide a valuable tool for 
Table 2. - Cell analysis of sputum samples

\begin{tabular}{lccccc}
\hline & MA & SA & COPD & \multicolumn{2}{c}{ Statistical analysis } \\
\cline { 4 - 6 } & & & MA/SA & MA/COPD & SA/COPD \\
\hline Squamous cells $\%$ & $4(2-9)$ & $8(3-20)$ & $9(1-40)$ & NS & NS \\
Total cell counts $\times 103 \cdot \mathrm{mL}^{-1}$ & $362(246-720)$ & $464(203-1010)$ & $790(575-1490)$ & $\mathrm{NS}$ & $\mathrm{NS}$ \\
Differential cell counts $\%$ & & & & $\mathrm{NS}$ \\
$\quad$ Macrophages & $16.5(14-34)$ & $2(13.3-31.3)$ & $10(4.5-19)$ & $\mathrm{p}<0.0004$ & $\mathrm{p}<0.001$ \\
Neutrophils & $68(41-80)$ & $50.5(19.5-60.5)$ & $58.5(40.5-84)$ & $\mathrm{NS}$ & $\mathrm{p}<0.003$ \\
Lymphocytes & $1(0-2)$ & $1(0-5.5)$ & $2(1-3.5)$ & $\mathrm{NS}$ & $\mathrm{NS}$ \\
Eosinophils & $1(1-3)$ & $2.5(1-13)$ & $1.5(0-4)$ & $\mathrm{NS}$ & $\mathrm{p}<0.009$ \\
Epithelial cells & $1(0-2)$ & $0(0-27)$ & $0(0-1)$ & $\mathrm{NS}$ & $\mathrm{NS}$ \\
\hline
\end{tabular}

Data are presented as median (interquartile range), unless otherwise stated. Statistical analysis was performed using the Mann-Whitney U-test and Bonferroni's correction. MA: mild asthma (untreated asthma); SA: severe asthma (corticosteroid-dependent asthma); COPD: chronic obstructive pulmonary disease; NS: nonsignificant.

Table 3. - Proteases/anti-proteases content in induced sputum

\begin{tabular}{|c|c|c|c|c|c|c|}
\hline & \multirow[t]{2}{*}{ MA } & \multirow[t]{2}{*}{ SA } & \multirow[t]{2}{*}{ COPD } & \multicolumn{3}{|c|}{ Statistical analysis } \\
\hline & & & & MA/SA & MA/COPD & SA/COPD \\
\hline Total elastase $\mu \mathrm{g} \cdot \mathrm{mL}^{-1}$ & $2(1-10.7)$ & $8(4.8-11)$ & $21(13.2-26.5)$ & NS & $\mathrm{p}=0.001$ & $\mathrm{p}=0.001$ \\
\hline Active elastase $\mu \mathrm{g} \cdot \mathrm{mL}^{-1}$ & $0.75(0.2-8.2)$ & $3.8(0.16-9.7)$ & $9.7(4.5-14)$ & NS & $\mathrm{p}=0.003$ & $\mathrm{p}=0.01$ \\
\hline$\alpha 1$-antitrypsin $\mu \mathrm{g} \cdot \mathrm{mL}^{-1}$ & $6(4-12)$ & $4(2.8-14.2)$ & $13.9(12.5-14.7)$ & NS & NS & $\mathrm{p}<0.004$ \\
\hline MMP-9 $\mu \mathrm{g} \cdot \mathrm{mL}^{-1}$ & $48(22-122)$ & $82(19-126.5)$ & $85(56.5-124)$ & NS & NS & NS \\
\hline TIMP-1 $\mu \mathrm{g} \cdot \mathrm{mL}^{-1}$ & $227(143-341)$ & $210(150-1935)$ & $900(484-1280)$ & NS & $\mathrm{p}=0.0007$ & NS \\
\hline MMP-9/TIMP-1 & $0.2(0.09-0.8)$ & $0.43(0.04-0.67)$ & $0.1(0.7-0.14)$ & NS & NS & NS \\
\hline
\end{tabular}

Data are expressed as median (interquartile range), unless otherwise stated. Statistical analysis was performed using the Mann-Whitney U-test and Bonferroni's correction. Data were considered statistically significant when $\mathrm{p}<0.016$. MA: mild asthma (untreated asthma); SA: severe asthma (corticosteroid-dependent asthma); COPD: chronic obstructive pulmonary disease; MMP: metalloproteinase; TIMP: tissue-inhibitor metalloproteinase; NS: nonsignificant.

the study and the differentiation of chronic airway diseases, as previously suggested by other investigators [42].

The main finding of the current study is the relationship between structural alterations documented with HRCT and biological markers of remodelling in severe asthmatics and in COPD; in other words, the more elastase levels increase and TIMP-1 overcomes MMP-9, the greater the magnitude of structural alterations. This observation may have some implications in the understanding of the pathophysiological processes of asthma and COPD, suggesting that a common feature of remodelling can be detected with structural consequences in the lungs, at least in these populations. To date, a body of evidence has accumulated information on the potential role of an increased proteolytic burden in the pathogenesis of structural and functional abnormalities associated with chronic inflammatory diseases of the airways $[47,48]$. Proteolytic enzymes have the potential to destroy lung structures and are responsible for the architectural damage that is seen in COPD [48]. An increased elastolytic activity seems also to occur in asthma, as shown by the presence of elastic fibre disruption in the bronchi of mild-tomoderate asthmatics [49]. The increased elastolytic activity in the airways of asthmatics could induce, to various extents, loss of the elastic recoil, increased collapsibility of the central airways, lack of distensibility of airways, and hyperinflation, thus variably contributing to the pathogenesis of airway remodelling and the development of exaggerated airway narrowing. It is also important to consider that the release of mediators, such as elastase, in asthma may reflect cellular activation. The current authors believe that this does not necessarily imply the presence of radiological findings suggestive of emphysema. Transmission electron microscopy studies have shown that an elastolytic process is also observed in fatal asthma, in which elastic fibre fragmentation is found in central airways [50]. Moreover, pseudophysiological emphysema has been found in chronic persistent asthma [51], which may depend upon an increased elastolysis.

Collagen homeostasis is also regulated by the proteolytic activity of MMPs, which is counterbalanced by their TIMPs $[4,52]$. It has been previously demonstrated that the MMP-9/ TIMP-1 ratio is reduced in asthmatic and COPD subjects as compared with normal subjects, and that it is significantly correlated with airway obstruction [2, 5]. Therefore, it was reasoned that an abnormal increase of TIMP-1 over MMP-9 levels may be a marker of airway remodelling [5, 8], reflecting a trend towards tissue fibrosis in the airways of these subjects. The present study confirms this hypothesis by demonstrating that the imbalance between MMP-9 and TIMP-1, together with levels of active elastase, is higher in those patients in whom the HRCT scan score is increased. This hypothesis is also supported by the inverse correlation between MMP-9/ TIMP-1 ratio and HRCT scan score, suggesting that TIMP-1 overproduction is involved in the development of airway remodelling in severe asthmatics and COPD subjects. Antitrypsin was also measured to assess whether a relationship exists between this factor and HRCT scan features of airway remodelling, and, in particular, those related with the destruction of the lung parenchyma. However, this analysis did not yield any significant relationship. The lack of such a relationship suggests that antitrypsin is a less sensitive marker to detect structural alterations of the lung.

The results of the current study have also shown that structural alterations of the airways and the parenchyma that are assessed with the HRCT are associated with lung function changes, as demonstrated by the significant correlation between FEV1 values and levels of active elastase; it is 

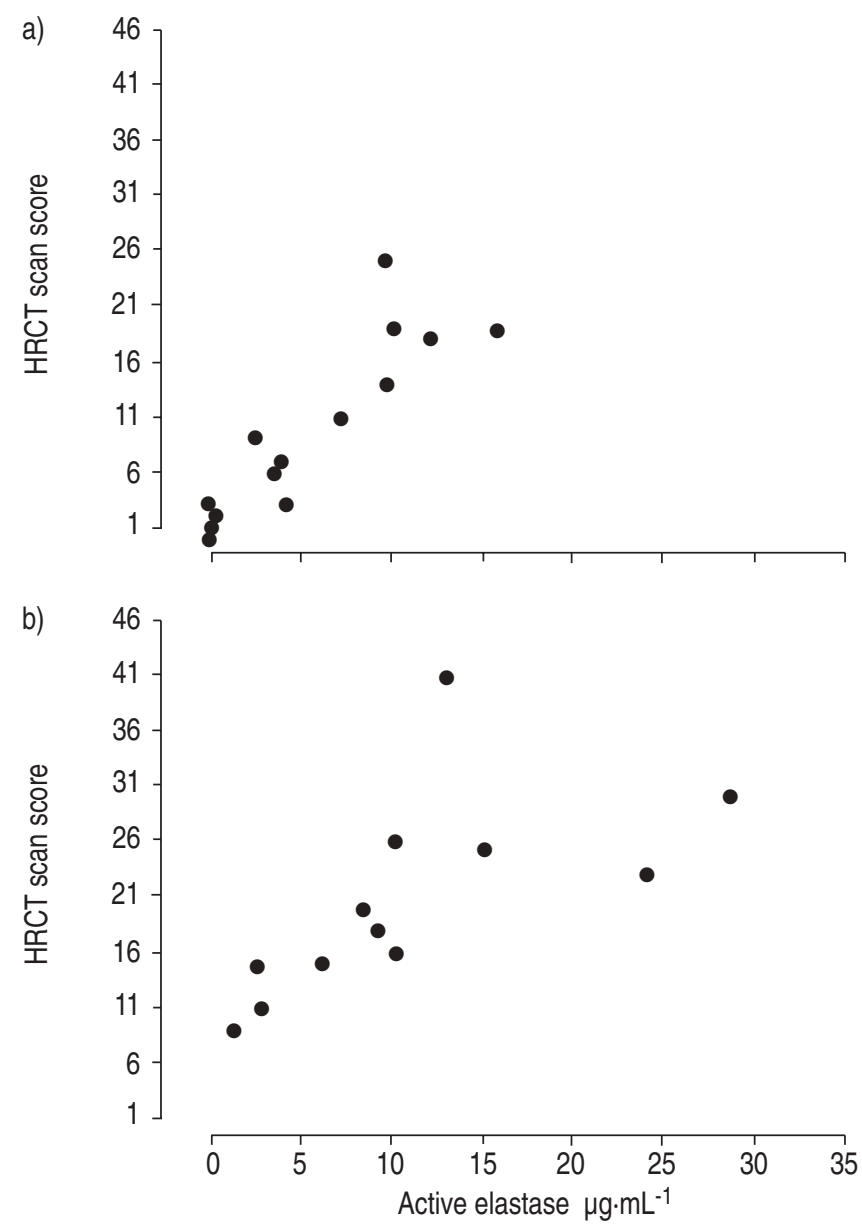

Fig. 3.-Correlations between the levels of active elastase and highresolution computed tomography (HRCT) scan score in a) severe asthmatic and b) chronic obstructive pulmonary disease subjects. Statistical analysis was performed using the Spearman rank test.

plausible that elastase, through the damage of the elastic fibres network both in central and peripheral airways, may be responsible for the reduced airways patency and elastic recoil during breathing [53]. This finding further suggests that airflow limitation in these subjects could be attributed not only to airway alterations, but also to parenchymal destruction, and provides a model that incorporates imaging and functional abnormalities with biological markers.

It is worth noticing that three severe asthmatics showed parenchymal alterations suggestive of emphysema. This might have influenced the results of the study and needs to be taken into account. The clinical characterisation of the patients was critical in this study. Although it is difficult to clearly separate some patients with COPD from asthmatics with permanent airflow limitation [54, 55], the appropriateness of the diagnosis is supported by the lack of response to inhaled $\beta$ adrenergic agents, as well as by lower $D \mathrm{~L}, \mathrm{CO}$ and $\mathrm{Pa}, \mathrm{O}_{2}$ values measured in the COPD group.

The impact of age on elastase and $\alpha 1$-antitrypsin has not been evaluated in the current study. However, the role of age seems to be ruled out by the current authors' recent observation that, in asthmatics, the alteration of the mechanisms involved in the degradation of elastin is not enhanced by the process of ageing [56]. An imbalance between proteinases and their inhibitors has also been reported in individuals with COPD, supporting the concept that this mechanism is a feature of chronic bronchitis. Therefore, the current authors feel confident that the disease status is the main determinant of the imbalance in the enzymatic activity. The present authors are also aware of the fact that structural alterations of the lung could be associated with ageing processes. Indeed, a re-arrangement of the elastic fibre network in the lungs of elderly individuals has been demonstrated [47]. However, the lung parenchyma of the elderly is characterised by a homogeneous enlargement of airspaces without destruction [57]. Therefore, the senile lung can be distinguished from the emphysematous lung, where the airspace enlargement has an irregular distribution with destruction. As a consequence, the disease condition (either asthma or COPD) is responsible for the radiological abnormalities, thus overcoming any possible impact of the age-related structural alterations.

In conclusion, the present study demonstrates a close relationship between high-resolution computed tomography scan alterations and changes in the levels of markers of airway remodelling, and suggests that biological markers might reflect the structural changes occurring in the airways. The use of high-resolution computed tomography to quantify the extent of in vivo remodelling alterations is encouraged.
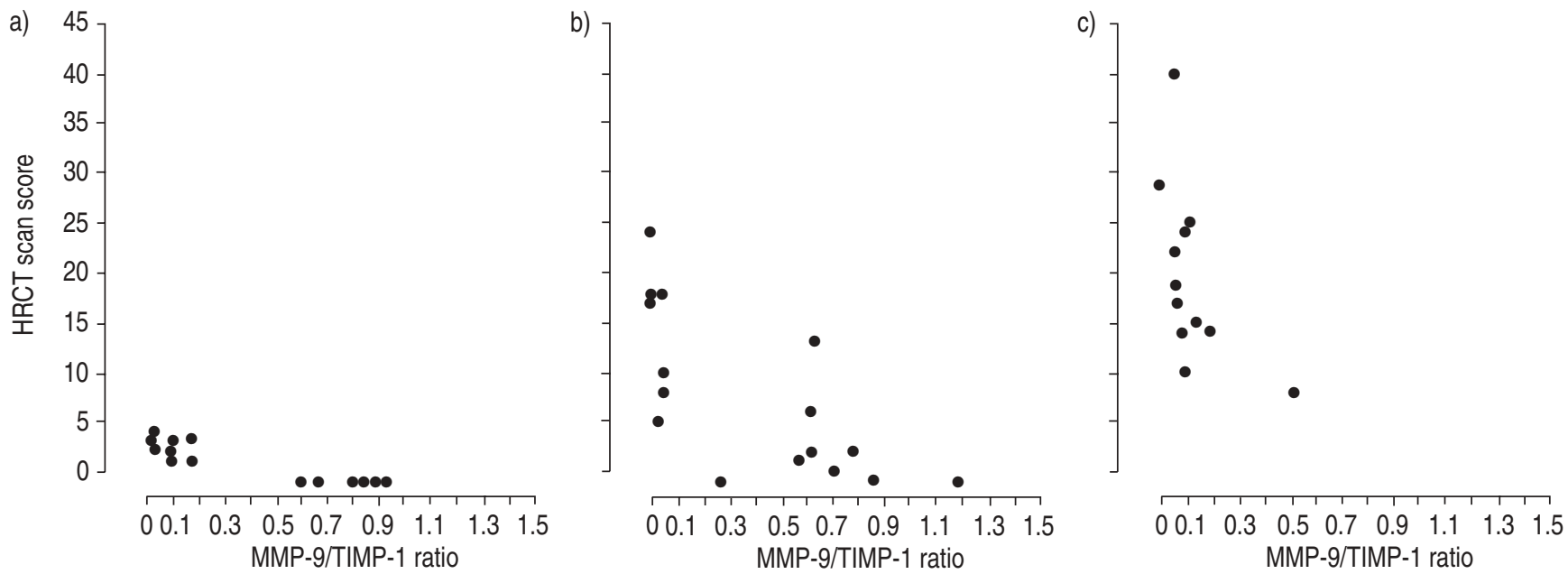

Fig. 4. - Correlations between the levels of metalloproteinase (MMP)-9/tissue-inhibitor metalloproteinase (TIMP)-1 ratio and high-resolution computed tomography (HRCT) scan score in a) mild asthma $(\rho=-0.8, p<0.003)$, b) severe asthma $(\rho=-0.7, p<0.004)$, and c) chronic obstructive pulmonary disease $(\rho=-0.6, p<0.04)$. Statistical analysis was performed using the Spearman rank test. 
Acknowledgements. The work benefited from the experience gained in the European Community Programme GA2LEN, Global Allergy and Asthma European Network.

\section{References}

1. Vignola AM, Kips J, Bousquet J. Tissue remodeling as a feature of persistent asthma. J Allergy Clin Immunol 2000; 105: 1041-1053.

2. Vignola AM, Bonanno A, Mirabella A, et al. Increased levels of elastase and $\alpha 1$-antitrypsin in sputum of asthmatic patients. Am J Respir Crit Care Med 1998; 157: 505-511.

3. Fujita J, Nelson NL, Daughton DM, et al. Evaluation of elastase and antielastase balance in patients with chronic bronchitis and pulmonary emphysema. Am Rev Respir Dis 1990; 142: 57-62.

4. Murphy G, Docherty AJ. The matrix metalloproteinases and their inhibitors. Am J Respir Cell Mol Biol 1992; 7: 120-125.

5. Vignola AM, Riccobono L, Mirabella A, et al. Sputum metalloproteinase-9/tissue inhibitor of metalloproteinase-1 ratio correlates with airflow obstruction in asthma and chronic bronchitis. Am J Respir Crit Care Med 1998; 158: 1945-1950.

6. Bousquet J, Jeffery PK, Busse WW, Johnson M, Vignola AM. Asthma. From bronchoconstriction to airways inflammation and remodeling. J Allergy Clin Immunol 2000; 105: $1720-1745$.

7. Cosio M, Ghezzo H, Hogg J, et al. The relations between structural changes in small airways and pulmonary function tests. N Engl J Med 1977; 298: 1277-1281.

8. Mautino G, Henriquet C, Jaffuel D, Bousquet J, Capony F. Tissue inhibitor of metalloproteinase-1 levels in bronchoalveolar lavage fluid from asthmatic subjects. Am J Respir Crit Care Med 1999; 160: 324-330.

9. Belvisi MG, Bottomley KM. The role of matrix metalloproteinases (MMPs) in the pathophysiology of chronic obstructive pulmonary disease (COPD): a therapeutic role for inhibitors of MMPs? Inflamm Res 2003; 52: 95-100.

10. Cataldo D, Munaut C, Noel A, et al. Matrix metalloproteinases and TIMP-1 production by peripheral blood granulocytes from COPD patients and asthmatics. Allergy 2001; 56: 145-151.

11. Park JW, Hong YK, Kim CW, Kim DK, Choe KO, Hong CS. High-resolution computed tomography in patients with bronchial asthma: correlation with clinical features, pulmonary functions and bronchial hyperresponsiveness. $J$ Investig Allergol Clin Immunol 1997; 7: 186-192.

12. Paganin F, Seneterre E, Chanez P, et al. Computed tomography of the lungs in asthma: influence of disease severity and etiology. Am J Respir Crit Care Med 1996; 153: 110-114.

13. Paganin F, Vignola AM, Seneterre E, Bruel JM, Chanez P, Bousquet J. Heterogeneity of airways obstruction in asthmatic patients using high-resolution computed tomography. Chest 1995; 107: Suppl. 3, 145S-146S.

14. Bergin C, Muller N, Nichols D, et al. The diagnosis of emphysema: a computed tomographic-pathologic correlation. Am Rev Respir Dis 1986; 133: 541-546.

15. Baldi S, Miniati M, Bellina C, et al. Relationship between extent of pulmonary emphysema by high-resolution computed tomography and lung elastic recoil in patients with chronic obstructive pulmonary disease. Am Rev Respir Dis 2001; 164: 585-589.

16. Niimi A, Matsumoto H, Amitani R, et al. Airway wall thickness in asthma assessed by computed tomography. Relation to clinical indices. Am J Respir Crit Care Med 2000; 162: 1518-1523.

17. Little S, Sproule M, Cowan M, et al. High resolution computed tomographic assessment of airway wall thickness in chronic asthma: reproducibility and relationship with lung function and severity. Thorax 2002; 57: 247-253.

18. American Thoracic Society. Definitions and classifications of chronic bronchitis, asthma and emphysema. Am Rev Respir Dis 1962; 85: 762-768.

19. WHO/NHLBI workshop report. Global strategy for asthma management and prevention. Bethesda, National Institutes of Health, National Heart, Lung and Blood Institute (publication no. 95-3659), 1995.

20. Gagliardo R, Chanez P, Vignola AM, et al. Glucocorticoid receptor alpha and beta in glucocorticoid dependent asthma. Am J Respir Crit Care Med 2000; 162: 7-13.

21. Juniper EF, Guyatt GH, Cox FM, Ferrie PJ, King DR. Development and validation of the Mini Asthma Quality of Life Questionnaire. Eur Respir J 1999; 14: 32-38.

22. Standards for the diagnosis and care of patients with chronic obstructive pulmonary disease (COPD) and asthma. This official statement of the American Thoracic Society was adopted by the ATS Board of Directors, November 1986. Am Rev Respir Dis 1987; 136: 225-244.

23. Bousquet J, Chanez P, Lacoste JY, et al. Eosinophilic inflammation in asthma. N Engl J Med 1990; 323: 1033-1039.

24. Knudson R, Slavin R, Lebowitz M, Burrows B. The maximum expiratory flow volume curve: normal standards, variability and effects of age. Am Rev Respir Dis 1976; 113: 587-600.

25. Cotes JE, Chinn DJ, Quanjer PH, Roca J, Yernault JC. Standardization of the measurement of transfer factor (diffusing capacity). Report Working Party Standardization of Lung Function Tests, European Community for Steel and Coal. Official Statement of the European Respiratory Society. Eur Respir J 1993; 6: Suppl. 16, 41-52.

26. Quanjer PH, Tammeling GJ, Cotes JE, et al. Symbols, abbreviations and units. Working Party Standardization of Lung Function Tests, European Community for Steel and Coal. Eur Respir J 1993; 6: Suppl. 16, 85-100.

27. Mayo JR, Webb WR, Gould R, et al. High-resolution CT of the lungs: an optimal approach. Radiology 1987; 163: 507510.

28. Seneterre E, Paganin F, Bruel JM, Michel FB, Bousquet J. Measurement of the internal size of bronchi using high resolution computed tomography (HRCT). Eur Respir $J$ 1994; 7: 596-600.

29. Webb WR, Gamsu G, Wall SD, Cann CE, Proctor E. CT of a bronchial phantom. Factors affecting appearance and size measurements. Invest Radiol 1984; 19: 394-398.

30. Lucidarme O, Grenier P, Coche E, Lenoir S, Aubert B, Beigelman C. Bronchiectasis: comparative assessment with thin-section CT and helical CT. Radiology 1996; 200: 673679.

31. Remy-Jardin M, Remy J. Comparison of vertical and oblique CT in evaluation of bronchial tree. $J$ Comput Assist Tomogr 1988; 12: 956-962.

32. Kim JS, Muller NL, Park CS, Grenier P, Herold CJ Cylindrical bronchiectasis: diagnostic findings on thinsection CT. AJR Am J Roentgenol 1997; 168: 751-754.

33. Stern EJ, Frank MS. CT of the lung in patients with pulmonary emphysema: diagnosis, quantification, and correlation with pathologic and physiologic findings. AJR $\mathrm{Am}$ J Roentgenol 1994; 162: 791-798.

34. Austin JH, Muller NL, Friedman PJ, et al. Glossary of terms for CT of the lungs: recommendations of the Nomenclature Committee of the Fleischner Society. Radiology 1996; 200: 327-331.

35. Eda S, Kubo K, Fujimoto K, Matsuzawa Y, Sekiguchi M, Sakai F. The relations between expiratory chest CT using helical CT and pulmonary function tests in emphysema. Am J Respir Crit Care Med 1997; 155: 1290-1294.

36. Reiff DB, Wells AU, Carr DH, Cole PJ, Hansell DM. CT findings in bronchiectasis: limited value in distinguishing between idiopathic and specific types. AJR Am J Roentgenol 1995; 165: 261-267. 
37. Paganin F, Trussard V, Seneterre E, et al. Chest radiography and high resolution computed tomography of the lungs in asthma. Am Rev Respir Dis 1992; 146: 1084-1087.

38. Pin I, Freitag AP, O'Byrne PM, et al. Changes in the cellular profile of induced sputum after allergen-induced asthmatic responses. Am Rev Respir Dis 1992; 145: 1265-1269.

39. Neumann S, Gunzer G, Hennrich N, Lang H. "PMNelastase assay": enzyme immunoassay for human polymorphonuclear elastase complexed with alpha 1-proteinase inhibitor. J Clin Chem Clin Biochem 1984; 22: 693-697.

40. Okazawa M, Muller N, McNamara A, Child S, Verburgt L, Pare P. Human airway narrowing measured using high resolution computed tomography. Am J Respir Crit Care Med 1996; 154: 1557-1562.

41. King G, Müller N, Paré P. Evaluation of airways in obstructive pulmonary disease using high-resolution computed tomography. Am J Respir Crit Care Med 1999; 159: 992-1004.

42. Nakano Y, Müller N, King G, et al. Quantitative assessment of airway remodeling using high-resolution CT. Chest 2002; 122: Suppl. 6, 271S-275S.

43. Niimi A, Matsumoto H, Amitani R, et al. Airway wall thickness in asthma assessed by computed tomography: relation to clinical indices. Am J Respir Crit Care Med 2000; 162: 1518-1523.

44. Boulet L, Belanger M, Carrier G. Airway responsiveness and bronchial-wall thickness in asthma with or without fixed airflow obstruction. Am J Respir Crit Care Med 1995; 152: 865-871.

45. Nakano Y, Muro S, Sakai H, et al. Computed tomographic measurements of airway dimensions and emphysema in smokers: correlation with lung function. Am J Respir Crit Care Med 2000; 162: 1102-1108.

46. Loubeyre P, Paret M, Revel D, Wiesendanger T, Brune J. Thin-section CT detection of emphysema associated with bronchiectasis and correlation with pulmonary function tests. Chest 1996; 109: 360-365.
47. Janoff A. Elastases and emphysema. Current assessment of the protease-antiprotease hypothesis. Am Rev Respir Dis 1985; 132: 417-433.

48. Stockley RA. The role of proteinases in the pathogenesis of chronic bronchitis. Am J Respir Crit Care Med 1994; 150: S109-S113.

49. Bousquet J, Lacoste J, Chanez P, Vic P, Godard P, Michel F. Bronchial elastic fibers in normal subjects and asthmatic patients. Am J Respir Crit Care Med 1996; 153: 16481653.

50. Mauad T, Xavier AC, Saldiva PH, Dolhnikoff M. Elastosis and fragmentation of fibers of the elastic system in fatal asthma. Am J Respir Crit Care Med 1999; 160: 968975.

51. Gelb AF, Zamel N. Unsuspected pseudophysiologic emphysema in chronic persistent asthma. Am J Respir Crit Care Med 2000; 162: 1778-1782.

52. Matrisian LM. The matrix-degrading metalloproteinases. Bioessays 1992; 14: 455-463.

53. Wright RR. Elastic tissue of normal and emphysematous lungs. A tridimentional histologic study. Am J Pathol 1961; 34: 355-363.

54. O'Connor GT, Sparrow D, Weiss ST. The role of allergy and nonspecific airway hyperresponsiveness in the pathogenesis of chronic obstructive pulmonary disease. Am Rev Respir Dis 1989; 140: 225-252.

55. Snider GL. Chronic obstructive pulmonary disease: a definition and implications of structural determinants of airflow obstruction for epidemiology. Am Rev Respir Dis 1989; 140: S3-S8.

56. Vignola AM, Bonanno A, Profita M, et al. Effect of age and asthma duration upon elastase and alpha1-antitrypsin levels in adult asthmatics. Eur Respir J 2003; 22: 795-801.

57. Verbeken E, Cauberghs M, Mertens I, Clement J, Lauwryns J, Van de Woestijne K. The senile lung: comparison with normal and emphysematous lungs. 1. Structural aspects. Chest 1992; 101: 793-799. 